\section{BMJ Open \\ Respiratory \\ Research}

\title{
Necessity of amoxicillin clavulanic acid in addition to prednisolone in mild-to- moderate COPD exacerbations
}

\author{
Marjolein Brusse-Keizer, ${ }^{1}$ Paul VanderValk, ${ }^{1}$ Ron Hendrix, ${ }^{2,3}$ Huib Kerstjens, ${ }^{4}$ \\ Job van der Palen ${ }^{1,5}$
}

To cite: Brusse-Keizer M, VanderValk P, Hendrix R, et al. Necessity of amoxicillin clavulanic acid in addition to prednisolone in mild-tomoderate COPD

exacerbations. BMJ Open Resp Res 2014;1:e00052. doi:10.1136/bmjresp-2014000052

Received 10 June 2014 Revised 13 November 2014 Accepted 16 November 2014

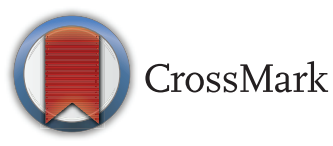

${ }^{1}$ Department of Pulmonary Medicine, Medisch Spectrum Twente, Enschede,

The Netherlands

${ }^{2}$ Regional Laboratory of

Public Health, Enschede,

The Netherlands

${ }^{3}$ Department of Medical Microbiology, University Medical Centre Groningen, and University of Groningen, Groningen, The Netherlands

${ }^{4}$ Department of Pulmonary

Medicine, and Groningen

Research Institute for Asthma and COPD (GRIAC),

University Of Groningen, University Medical Centre Groningen, Groningen, The Netherlands

${ }^{5}$ Department of Research Methodology, Measurement, and Data Analysis, University of Twente, Enschede,

The Netherlands

Correspondence to Dr Marjolein Brusse-Keizer; m.brusse-keizer@mst.nl

\section{ABSTRACT}

Background: The effectiveness of antibiotics in chronic obstructive pulmonary disease (COPD) exacerbations is still a matter of debate, especially in outpatients with an intermediate probability of bacterial infection.

Methods: In this study, 35 COPD outpatients diagnosed by their chest physician with moderately severe COPD exacerbation, but without pneumonia, were randomised in a double blind, placebo-controlled study. Patients had one or two of the following characteristics: a positive Gram's stain of the sputum, 2 or more exacerbations in the previous year, a decrease in lung function of $>200 \mathrm{~mL}$ and $>12 \%$. Patients received amoxicillin clavulanic acid $(500 / 125 \mathrm{mg}$ three times daily) or placebo for 7 days, always combined with a course of prednisolone ( $30 \mathrm{mg} /$ day) for 7 days. Primary outcome was duration of the exacerbation.

Additionally, we measured severity of the exacerbation, health-related quality of life, sputum parameters, number of relapses within 28 days and the number of re-exacerbations within 4 months after the study.

Results: There was no difference observed in time to resolution of the exacerbation between the two groups ( $\mathrm{HR}=1.12 ;(95 \% \mathrm{Cl} 0.5$ to $2.3 ; \mathrm{p}=0.77))$, nor in any other treatment parameter.

Conclusions: We detected no evidence for the effectiveness of addition of antibiotics to prednisolone for COPD exacerbations of moderate severity and with intermediate probability of bacterial infection in this underpowered study. More placebo-controlled studies are needed to properly define subgroups of COPD outpatients in which antibiotics are of additional value. Trials registration number: clinical trial registered with http://www.trialregister.nl/(NTR351).

\section{INTRODUCTION}

Chronic obstructive pulmonary disease (COPD) is characterised by acute exacerbations (AECOPD) that are associated with substantial morbidity and mortality. ${ }^{1-3}$ Management of AECOPD includes oral corticosteroids often combined with broad spectrum antibiotics to treat a presumed bacterial infection. ${ }^{4}$ Some

\section{KEY MESSAGES}

No evidence for effectiveness of addition of antibiotics to prednisolone for AECOPD with moderate severity and intermediate probability of bacterial infection was observed.

- More placebo-controlled studies to define subgroups of COPD outpatients in which antibiotics are of additional value are needed.

antibiotics, especially the macrolides, are also sometimes provided prophylactically for longer term use due to their anti-inflammatory, immunomodulatory or antiviral effects. ${ }^{5}$ A short course of broad spectrum antibiotics during AECOPD is, however, mainly used for their antibacterial effect. Their use remains controversial due to several reasons. First only approximately one-third of AECOPD are due to bacterial infections. ${ }^{6}$ Second, given the existence of bacterial infections, the treatment is empirical since culture and resistance results usually take 1 week to become available. Third, growing resistance against antibacterial agents is an additional reason to be reluctant to give a prescription of antibiotics. ${ }^{7} 8$ Finally and perhaps most importantly, there is no definitive evidence that antibiotics offer benefits in outpatients with mild-to-moderate AECOPD. ${ }^{9} 10$

The latest international guidelines recommend antibiotics to patients with AECOPD who have three cardinal symptoms (increase in dyspnoea, sputum volume and sputum purulence); patients who have two of the cardinal symptoms, if increased purulence of sputum is one of the two symptoms; or to patients who require mechanical ventilation (invasive or non-invasive).$^{11}$ These criteria originated from the study by Anthonisen $e t a l^{12}$ which showed only a marginal benefit from antibiotics in a subgroup of patients. They divided AECOPD into three categories and concluded that in case of the presence of all three of the above 
mentioned criteria (type I) the cause of the AECOPD is probably bacterial and is more likely to have a favourable outcome with antibiotics. ${ }^{12}$

Unfortunately, most placebo-controlled antibiotics trials, on which these guidelines are based, have important limitations and are difficult to compare because of different definitions of COPD and AECOPD, and different end points that have been used. ${ }^{13}{ }^{14}$ Furthermore, these trials were conducted several decades ago, before systemic steroids were widely introduced for the treatment of AECOPD. ${ }^{15-18}$ Even in the recently published study by Llor et $a l^{19}$ in which a beneficial effect with amoxicillin/clavulanic acid compared to placebo was observed, only $17 \%$ of the patients were treated with systemic steroids. ${ }^{20}$ Furthermore, as stated in the Cochrane Review of Vollenweider et al, when the analyses on the effects of antibiotics are restricted to currently used drugs, antibiotics do not significantly reduce treatment failure in outpatient AECOPDs.

Van der Valk $e t a l^{21}$ reported that an Anthonisen type I AECOPD did not predict a bacterial origin of an outpatient's AECOPD and that sputum purulence was poorly associated with bacterial infection. This study did, however, found that the combination of a positive Gram's stain of sputum, a clinically relevant lung function decrease and $\geq$ two AECOPDs in the previous year were $67 \%$ predictive for a bacterial origin of the AECOPD and therefore, postulated to warrant antibiotic treatment. The absence of all three characteristics gave a negative predictive value of $100 \%$ for a non-bacterial origin, suggesting to abstain from administering the antibiotics. ${ }^{21}$ This leaves patients with one or two of these characteristics. Therefore, in the current double-blind, randomised, placebo-controlled study, we evaluated the effect of an antibiotic on the duration and severity of AECOPDs in outpatients with one or two of the three mentioned characteristics.

\section{METHODS}

\section{Patients}

Patients with COPD were recruited from May 2005 till January 2007 from the outpatient pulmonary clinic of Medisch Spectrum Twente, Enschede, The Netherlands. Patients had to meet the following criteria: (1) a diagnosis of COPD according to the GOLD-criteria; (2) current or ex-smoker; (3) age 40-80 years; (4) presenting at the outpatient clinic with an AECOPD, defined as an acute negative change in dyspnoea and/or sputum volume and/or colour of sputum (yellowish or greenish) and/ or cough, which warrants additional treatment with prednisolone with or without antibiotics by a physician; (5) no requirement of hospitalisation (6) no pneumonia based on chest X-ray; ${ }^{22}(7)$ ability to produce a spontaneous sputum sample; (8) presenting with one or two of the clinical characteristics: a positive Gram's stain of sputum, a clinically relevant lung function decrease (decrease in $\mathrm{FEV}_{1}$ of $\geq 200 \mathrm{~mL}$ and $\geq 12 \%$ from baseline), or $\geq 2$ AECOPDs in the previous year; ${ }^{21}$ (9) no AECOPD or use of antibiotics or prednisolone 4 weeks prior to enrolment, except for low-dose prednisolone $(\leq 5 \mathrm{mg})$ as maintenance therapy; (10) no disease that influences bronchial symptoms or lung function; (11) no maintenance therapy with antibiotics; (12) no known hypersensitivity to amoxicillin/ clavulanic acid; (13) no medical condition with low survival or serious psychiatric morbidity; (14) no uncontrolled diabetes mellitus; (15) no need for domiciliary oxygen therapy; and (16) no participation in another clinical trial.

The hospital's medical ethics committee approved the study. All patients provided written informed consent.

\section{Study design}

This study was a randomised, double blind, placebocontrolled study. Eligible patients were randomly assigned in a one-to-one ratio to either the intervention or control group based on a computer generated randomisation list. The hospital pharmacy provided both amoxicillin/clavulanic acid and placebo in identical containers with identical capsules. Based on the randomisation list, the hospital pharmacy sequentially numbered the containers with both amoxicillin/clavulanic acid and placebo. This list was kept in a safe at the hospital pharmacy throughout the course of the study. Patients received these numbered containers in sequence of randomisation, which was recorded on a medication distribution list.

Patients in both groups received oral prednisolone, $30 \mathrm{mg} /$ day for 7 days. Patients in the intervention group additionally received oral amoxicillin/clavulanic acid (Augmentin) 500/125 mg three times daily for 7 days, while control patients received a matching placebo. The choice for this amoxicillin/clavulanic acid is based on the negligible prevalence of organisms resistance in our region (less than 5\%). All patients continued their prescribed inhaled regimen. Patients were followed for 28 days for the primary outcome and for 4 months to detect new AECOPDs.

\section{Outcome measures}

The primary outcome was the duration of the AECOPD. Start of the AECOPD was defined as the day the patient presented with an AECOPD at the outpatient clinic. The end day of the AECOPD was based on a symptom diary, which patients completed daily. ${ }^{23}$ In this diary, patients reported whether their major symptoms and minor symptoms, according to Anthonisen et al ${ }^{12}$ (table 1), were beyond normal. At inclusion all patients received a 'what is normal' card on which their individual levels of major symptoms in stable health state were recorded. This card was used as a reference for the diary. When patients experienced no increase in severity of any symptoms listed in the diary, they could tick 'no change in symptoms'. In all other cases, they had to report on all the symptoms in the diary - whether the level of each symptom was normal, whether there was a small increase or an evident increase in severity compared to their stable state.

The last day of the AECOPD was defined as the first day of: (1) three consecutive days when the patient had 


\begin{tabular}{|c|c|c|c|}
\hline & Normal & Small increase & Evident increase/change \\
\hline \multicolumn{4}{|l|}{ Major symptoms } \\
\hline Dyspnoea & 0 & 1 & 2 \\
\hline Sputum production & 0 & 1 & 2 \\
\hline Sputum colour & 0 & & $2^{*}$ \\
\hline \multicolumn{4}{|l|}{ Minor symptoms } \\
\hline Cough & 0 & 0.5 & 1 \\
\hline Wheeze & 0 & 0.5 & 1 \\
\hline Running nose & 0 & 0.5 & 1 \\
\hline Sore throat & 0 & 0.5 & 1 \\
\hline Fever & 0 & & $1 \dagger$ \\
\hline
\end{tabular}

returned to his normal health state; or (2) seven consecutive days in which patients only reported a minor increase in symptoms compared to baseline, without fever or changed sputum colour.

Secondary outcome measures were the severity of the AECOPD, number of relapses of AECOPDs within 28 days, number of AECOPDs within 4 months, lung function parameters, sputum parameters and HRQoL.

Severity of the AECOPD was based on the symptom scores in the diary and was calculated as predefined in the protocol. On each day of the AECOPD, a severity score was calculated (table 1). Adding the symptom scores resulted in a daily score ranging from 0 to 11 points. A mean severity score per AECOPD day was calculated by dividing the sum scores of each AECOPD day by the number of days the AECOPD lasted. ${ }^{23}$

A relapse was defined as an AECOPD that resolved following the blinded treatment but re-occurred within 28 days of the treated AECOPD. The number of AECOPDs within 4 months was estimated by counting the number of courses of prednisolone and antibiotics prescribed for lung-associated illness, based on data from pharmacy records. In our region this provides a very accurate coverage of consumption. Pharmacy data were similarly used to determine the number of AECOPDs in the year prior to the start of the study.

At the start of the study and after 28 days, lung function was measured. Spontaneous sputum samples were collected and sputum colour was determined according to the Stockley protocol nine-point colour chart (BronkoTest, Heredilab Inc, Salt Lake City, Utah, USA). ${ }^{24}$ Sputum with a colour value $\leq 2$ was defined as 'mucoid' and sputum colour $\geq 3$ was defined as 'purulent'. Subsequently, a Gram's stain and a semiquantitative culture were made. Infection was defined by the presence of potentially pathogenic micro-organisms (PPM) in pure culture or by the presence of one or more PPM in excess (one log or more) to background microbiological flora in sputum. ${ }^{21}{ }^{25}$ Bacterial colonisation was defined as the presence of PPM in culture in equal amount or less compared to background microbiological flora in sputum.
The level of PCT was measured in blood samples that were derived at the start. PCT levels were assessed with an automated sandwich immunoassay using a time-resolved amplified cryptate emission technology (TRACE; Kryptor PCT; Brahms AG; Hennigsdorf, Germany).The PCT assays has a detection limit of $0.02 \mathrm{ng} / \mathrm{mL}$ and a functional assay sensitivity of $0.06 \mathrm{ng} / \mathrm{mL}$. PCT levels were also divided based on the cut-off levels determined by Stolz et $a l^{26}$ that were set at $>0.1 \mu \mathrm{g} / \mathrm{L}$, between $0.1-0.25 \mu \mathrm{g} / \mathrm{L}$ and $>0.25 \mu \mathrm{g} / \mathrm{L}$.

HRQoL was measured by means of the Chronic Respiratory Questionnaire (CRQ) ${ }^{27}$ Health status was measured with the Clinical COPD Questionnaire (CCQ). ${ }^{28} 29$

\section{Statistical analysis}

With an expected mean duration of an exacerbation of approximately 15 days, a difference of 3 days in the duration of AECOPD between the treatment groups was defined prior to the study as clinically relevant. With a SD of 4 days, power of $80 \%$, and $\alpha$ of $5 \%, 58$ patients were required to detect this difference.

The relation between treatment and the duration of the AECOPD was analysed by Cox-regression analysis. To identify continuous variables that were different between treatment group, $\mathrm{t}$ tests or Mann-Whitney $\mathrm{U}$ test for the normally and not normally distributed variables were performed. Between-group comparisons of categorical variables were performed by $\chi^{2}$ tests or Fisher's exact tests, as appropriate. The a priori list of potential confounding variables is displayed in table 2 . Only variables different by treatment group $(p \leq 0.20)$ were tested for an association with duration of the AECOPD. Variables associated with duration of the AECOPD with $\mathrm{p} \leq 0.20$ were considered as potential confounders in the relation between treatment and duration of the AECOPD, and were entered into the multivariate Cox-regression analysis. Time to resolution was displayed as a Kaplan-Meier graph.

\section{RESULTS}

Of 63 potentially eligible patients with an AECOPD, 35 patients were randomised; 18 received amoxicillin/ 
Table 2 Baseline characteristics of the two treatment groups

\begin{tabular}{|c|c|c|c|}
\hline & $\begin{array}{l}\text { Amoxicillin/clavulanic } \\
\text { acid } \\
\mathrm{N}=18\end{array}$ & $\begin{array}{l}\text { Placebo } \\
\mathrm{N}=17\end{array}$ & p Value \\
\hline Gender (number of men (\%)) & $9(50)$ & $12(71)$ & 0.21 \\
\hline Smoking status (number (\%)) & & & 0.42 \\
\hline Ex-smokers & $14(78)$ & $11(65)$ & \\
\hline Current smokers & $4(22)$ & $6(35)$ & \\
\hline Age (median (range)) & $68(54-74)$ & $65(47-76)$ & 0.38 \\
\hline \multicolumn{4}{|l|}{ Lung function postbronchodilation at inclusion (SD) } \\
\hline $\mathrm{FEV}_{1}$ in litres & $1.24(0.44)$ & $1.53(0.54)$ & 0.06 \\
\hline $\mathrm{FEV}_{1} \%$ predicted & $44.7(15.4)$ & $52.2(15.1)$ & 0.16 \\
\hline $\mathrm{FEV}_{1} / \mathrm{VC} \%$ & $38.3(13.0)$ & $42.9(11.2)$ & 0.27 \\
\hline Positive Gram's stain (number (\%)) & $15(83)$ & $15(88)$ & 1.00 \\
\hline Sputum culture at inclusion (Number (\%)) & & & 0.18 \\
\hline No colonisation nor infection & $3(17)$ & $5(29)$ & \\
\hline Colonisation & $2(11)$ & $5(29)$ & \\
\hline Infection & $13(72)$ & $7(41)$ & \\
\hline AECOPDs in the previous year (number (\%)) & & & 0.63 \\
\hline$<2$ AECOPDs & $7(39)$ & $8(47)$ & \\
\hline$\geq 2$ AECOPDs & $11(61)$ & $9(53)$ & \\
\hline $\begin{array}{l}\text { Lung function decline of } \geq 200 \mathrm{~mL} \text { and } \geq 12 \% \text { at start of AECOPD } \\
\text { compared to baseline* (number }(\%) \text { ) }\end{array}$ & $2(11)$ & $2(12)$ & 1.00 \\
\hline Sputum colour score† (SD) & $4.4(1.2)$ & $3.4(1.1)$ & 0.02 \\
\hline Purulent sputum (number (\%)) & $17(94)$ & $13(77)$ & 0.17 \\
\hline Type of AECOPD according to Anthonisen (number (\%)) & & & 0.44 \\
\hline Type I (3 major symptoms) & $15(83)$ & $12(71)$ & \\
\hline Type II (2 major symptoms) & $3(17)$ & $5(29)$ & \\
\hline Type III (1 major+1 minor symptom) & 0 & 0 & \\
\hline Procalcitonin level $(\mu \mathrm{g} / \mathrm{L})$ (median (range)) & $0.06(0.03-0.22)$ & $0.06(0.04-0.11)$ & 0.42 \\
\hline Procalcitonin cut-off level (number (\%)) & & & 1.00 \\
\hline$<0.1 \mu \mathrm{g} / \mathrm{L}$ & $17(94)$ & $16(94)$ & \\
\hline $0.1-0.25 \mu \mathrm{g} / \mathrm{L}$ & $1(6)$ & $1(6)$ & \\
\hline$>0.25 \mu \mathrm{g} / \mathrm{L}$ & 0 & 0 & \\
\hline \multicolumn{4}{|c|}{$\begin{array}{l}\text { To identify variables that were different by treatment group, } t \text { tests in case of normally distributed variables were performed. For not normally } \\
\text { distributed variables this was performed by Mann-Whitney U test. Between-group comparisons of categorical variables were performed by } \chi^{2} \\
\text { tests or Fisher's Exact tests as appropriate. } \\
\text { "Baseline lung function was an earlier in stable state performed lung function measurement. } \\
\text { †Score according to the Stockley protocol with the nine-point colour chart (Bronko Test, Heredilab Inc, Salt Lake City, Utah, USA). } \\
\text { AECOPD, acute exacerbations chronic obstructive pulmonary disease; FEV }{ }_{1} \text {, forced expiratory volume in } 1 \mathrm{~s} \text {; VC, vital capacity. }\end{array}$} \\
\hline
\end{tabular}

clavulanic acid and 17 placebo (figure 1). All patients completed the treatment and follow-up. Baseline

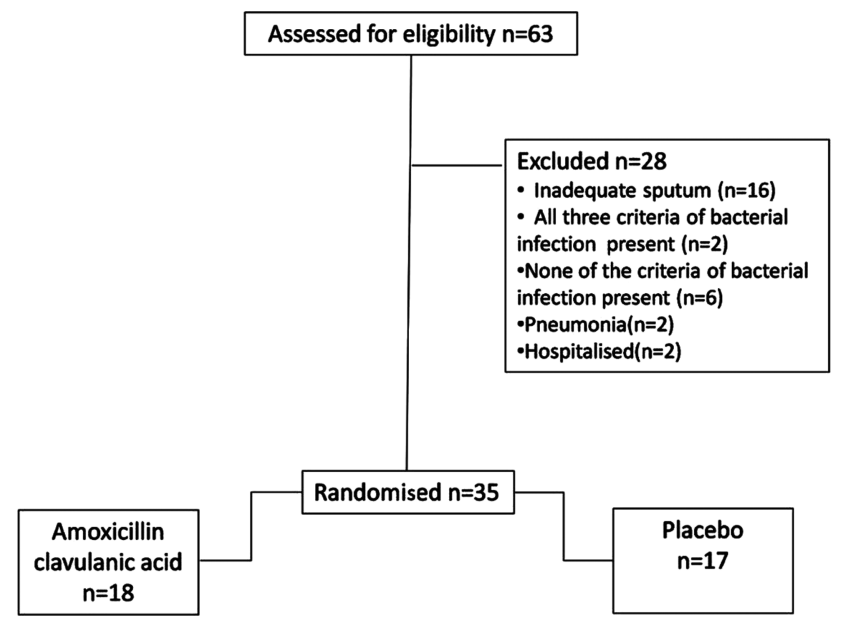

characteristics are displayed in table 2. At baseline, $\mathrm{FEV}_{1}$ (in litres and as \% predicted), sputum culture, colour and purulence showed to be potential confounders since these were associated to treatment with $\mathrm{p}<0.20$. Therefore, these variables were tested for association with the duration of treatment (also $\mathrm{p}<0.20)$. Since this was not the case for any variable, no adjustment of treatment effect on the duration of the AECOPD was necessary.

In 15 patients $(83 \%)$ in the intervention group, the AECOPD resolved within 28 days compared to 14 patients $(82 \%)$ that received placebo (see table 3). Since not all of the AECOPDs resolved within 28 days, we were not able to calculate the mean duration of the AECOPD. Therefore, we calculated the median time till resolution which was 7 days $(95 \%$ CI 2.8 to 11.2$)$ in the amoxicillin group compared to 10 days $(95 \%$ CI 3.3 to $16.7)$ in the placebo group $(\mathrm{p}=0.75)$.

The crude HR of time to resolution of the AECOPD in patients in the intervention group was 1.12 (95\% CI

Figure 1 CONSORT flow chart diagram. 


\begin{tabular}{|c|c|c|c|}
\hline & $\begin{array}{l}\text { Amoxicillin/clavulanic } \\
\text { acid } \\
(\mathrm{N}=18)\end{array}$ & $\begin{array}{l}\text { Placebo } \\
(\mathrm{N}=17)\end{array}$ & p Value \\
\hline Resolution of AECOPD within 28 days (number (\%)) & $15(83)$ & $14(82)$ & 1.00 \\
\hline Daily AECOPD severity score (median (range)) & $5.7(4.3-7.8)$ & $5.4(2.4-8.4)$ & 0.70 \\
\hline $\begin{array}{l}\text { Number of AECOPD days with a severity score } \geq 6 \\
\text { (median (range)) }\end{array}$ & $3(0-25)$ & $3(0-24)$ & 0.68 \\
\hline Relapse within 28 days (Number (\%)) & $2(11)$ & $1(6)$ & 1.0 \\
\hline $\begin{array}{l}\text { Number of AECOPDs within } 4 \text { months after end of study } \\
\text { (number }(\%) \text { ) }\end{array}$ & & & 0.66 \\
\hline 0 & 7 (39) & $10(59)$ & \\
\hline 1 & $6(33)$ & $4(24)$ & \\
\hline 2 & $4(22)$ & $3(18)$ & \\
\hline 3 & $1(16)$ & $0(0)$ & \\
\hline \multicolumn{4}{|l|}{ Change in CCQ scores from inclusion to day 28 (mean (SD)) } \\
\hline Total & $-2.3(2.7)$ & $-2.3(2.7)$ & 0.88 \\
\hline Mental state & $-0.6(1.5)$ & $-0.3(1.3)$ & 0.55 \\
\hline Functional state & $-0.6(1.0)$ & $-0.8(1.0)$ & 0.72 \\
\hline Symptom & $-1.2(1.4)$ & $-1.2(1.4)$ & 0.92 \\
\hline \multicolumn{4}{|l|}{ Change in CRQ scores from inclusion to day 28 (mean (SD)) } \\
\hline Dyspnoea & $0.5(1.3)$ & $0.5(1.6)$ & 0.91 \\
\hline Fatigue & $1.2(1.2)$ & $0.4(1.3)$ & 0.07 \\
\hline Emotional function & $0.1(0.9)$ & $0.6(1.2)$ & 0.23 \\
\hline Mastery & $0.3(1.4)$ & $0.4(1.4)$ & 0.94 \\
\hline \multicolumn{4}{|c|}{ Change in lung function postbronchodilation from inclusion to day 28 (mean (SD)) } \\
\hline $\mathrm{FEV}_{1}$ in litres & $0.02(0.21)$ & $0.07(0.27)$ & 0.51 \\
\hline FEV ${ }_{1} \%$ predicted & $1.6(8.8)$ & $2.4(8.9)$ & 0.80 \\
\hline Change in sputum colour from inclusion to day 28 (mean (SD)) ${ }^{*}$ & $-0.46(1.1)$ & $0.2(2.7)$ & 0.39 \\
\hline $\begin{array}{l}\text { Change in sputum purulence from inclusion to day } 28 \\
\text { (number (\%)) }\end{array}$ & & & 0.57 \\
\hline Mucoid to mucoid & $1(6)$ & $2(12)$ & \\
\hline Mucoid to purulent & 0 & $2(12)$ & \\
\hline Purulent to purulent & $11(61)$ & $8(47)$ & \\
\hline Purulent to mucoid & $6(33)$ & $5(29)$ & \\
\hline Procalcitonin level ( $\mu \mathrm{g} / \mathrm{L})$ (median (range)) & $0.06(0.03-0.26)$ & $0.05(0.03-0.24)$ & 0.28 \\
\hline Procalcitonin cut-off level (number (\%)) & & & 0.48 \\
\hline$<0.1 \mu \mathrm{g} / \mathrm{L}$ & $15(83)$ & $16(94)$ & \\
\hline $0.1-0.25 \mu \mathrm{g} / \mathrm{L}$ & $2(11)$ & $1(6)$ & \\
\hline$>0.25 \mu \mathrm{g} / \mathrm{L}$ & $1(6)$ & 0 & \\
\hline
\end{tabular}

0.54 to $2.32 ; \mathrm{p}=0.77)$ compared to the placebo group (figure 2).

Table 3 shows that there were no differences in any of the other treatment effects between the groups.

\section{Additional analyses}

Seventy-nine per cent and $82 \%$ of the patients in the intervention and placebo group, respectively, thought they had received placebo.

At inclusion the treating physician of each patient was asked what would have been prescribed had the patient not participated in the trial. In $34 \%$ of patients, the physician would have treated the patient with prednisolone only and in $66 \%$, with both prednisolone and antibiotics.

\section{DISCUSSION}

This randomised, placebo-controlled trial demonstrated no difference in time taken for the resolution of AECOPDs in outpatients treated with either amoxicillin/ clavulanic acid or placebo in addition to prednisolone. Also no difference in severity, number of relapses, number of AECOPDs 4 months after the study or HRQoL was observed. These conclusions apply only to patients with one or two of the following characteristics: 


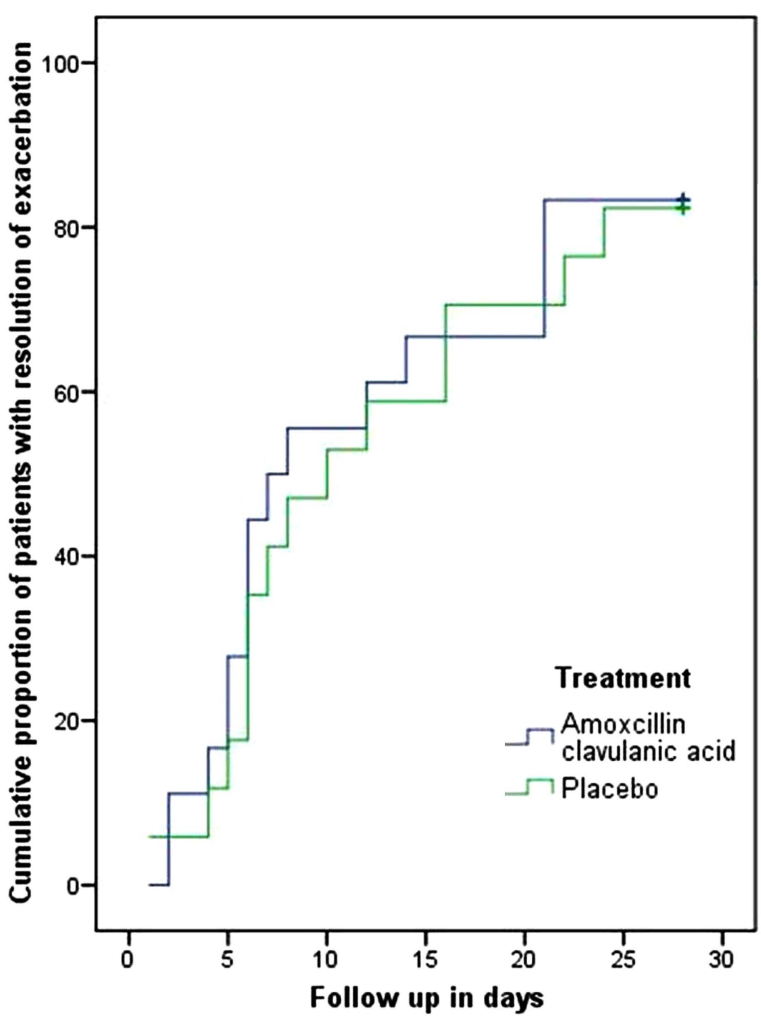

Figure 2 Kaplan-Meier graph showing time to resolution for both treatment groups.

a positive Gram's stain of sputum, a clinically relevant lung function decrease, and two or more AECOPDs in the previous year.

As detailed in the introduction, there is a paucity of good placebo-controlled studies on the effect of antibiotics in AECOPDs in addition to the treatment with systemic steroids.

Though there are large differences in prescription routines between and within countries, many physicians tend to err on the 'safe' side and therefore, also give antibiotics. In the current trial too we observed that $66 \%$ of the patients would have been treated with antibiotics by their physician. This routine has implications for costs, adverse effects and for the surge in antibiotic resistance $^{12}$ especially. Therefore, evidence needs to be established also in the group with less severe AECOPDs.

Anthonisen et al performed post hoc analyses stating that type I AECOPDs were likely to be bacterial and have a more favourable outcome with antibiotics. They stated that antibiotics confer no benefit in type III AECOPDs and that treatment of type II AECOPDs with antibiotics probably could be justified in case of antibiotic tolerance. ${ }^{24}$ A remarkable finding in our study was that a bacterial infection was present in only $15(56 \%)$ of the 27 type I AECOPDS. Additionally, although 15 $(83 \%)$ and $12(71 \%)$ of the AECOPDs in the amoxicillin/clavulanic acid and the placebo group, respectively, were type I Anthonisen, no effect from antibiotics was observed. These results give food for thought about the effectiveness of antibiotics in this type of AECOPD. The main difference between the study by Anthonisen and ours is the concomitant use of prednisolone, which is the standard recommendation nowadays. In the Anthonisen study only $42 \%$ received systemic steroids. The authors state that the success rate with antibiotics was favourable in both steroid and non-steroid users, but no data are provided. We believe that room for improvement by antibiotics will generally be less in patients treated with prednisolone, certainly in those with less severe AECOPDs.

Besides the type of Anthonisen AECOPD, we also measured PCT since this has been shown to be a marker of systemic bacterial infection. ${ }^{30}$ In the study of Stolz et $a l,{ }^{31}$ PCT was also elevated at hospitalisation for AECOPD. One study suggested that PCT can be used as criterion for decisions on whether to start antibiotics. ${ }^{26}$ However, this could not be reproduced in another study. ${ }^{32}$ In our study, in which instead of hospitalised AECOPD patients, outpatients with an AECOPD were included, we observed that $20(57 \%)$ of our patients with an AECOPD experienced a bacterial infection but that only $2(6 \%)$ had a PCT level between 0.1 and $0.25 \mu \mathrm{g} / \mathrm{L}$, which indicates possible bacterial infection. None of the patients had a PCT level $>0.25 \mu \mathrm{g} / \mathrm{L}$ which suggests the presence of bacterial infection. Therefore, our results suggest that PCT is not an informative biomarker as a criterion for decisions on whether to start antibiotics in outpatient AECOPD with an intermediate probability of infection.

In this study we observed that even though $57 \%$ of the patients experienced a bacterial infection, antibiotics had no added value in these patients. Although this suggests refraining from administering antibiotics in outpatient AECOPDs, this inference should not be generalised from our data to all outpatients, since our patients were selected for not having a high probability of bacterial infection. ${ }^{21}$ We believe, however, that our results merit a supplementary randomised, placebo-controlled trial in patients with a high probability of an AECOPD of bacterial origin.

In our additional analyses, we observed that the large majority of patients on antibiotics thought they had received placebo $(79 \%)$ which was very similar to the percentage in the group that really received placebo $(82 \%)$. This suggests that the patients were not aware of any effect that could be caused by the antibiotics.

An important limitation of this study is the number of patients included. Based on our power calculation, we needed to include 58 patients to be able to detect a difference of 3 days in AECOPD duration between the treatment groups. We were able to include only 35 patients within the time allotted. The majority of patients were not eligible due to: their participation in the COPE II study, ${ }^{23}$ an AECOPD or use of antibiotics or prednisolone 4 weeks prior to enrolment or their inability to produce a spontaneous sputum sample. However, with the observed HR of 1.12 and the median time to resolution of 10 days in the control group, the required sample size 
would be 2450 patients. With this enormous number of patients we might have found a significant difference, but we suggest that this difference would not be clinically relevant. We, therefore, feel that the lack of effect of antibiotics is not completely based on not including 58 patients. We should, however, realise that due to the smaller number of patients included, the probability of a type II error - not rejecting the null hypothesis in case of a difference between arms - in this study will be higher than the $20 \%$ based on the power of $80 \%$.

\section{CONCLUSION}

In conclusion, this underpowered, randomised, placebocontrolled study observed no added value of treatment with antibiotics in outpatients with moderate to severe AECOPDs and intermediate probability of infection. Instead of more equivalence trials comparing two antibiotics, we need more placebo-controlled studies to determine whether we can properly define subgroups of COPD outpatients in which antibiotics indeed are of additional value and in whom there is no use at all.

Acknowledgements The authors thank the Research Department of Thermofischer, Hennigsdorf, Berlin, for supplying the PCT kits and the use of the Kryptor.

Contributors MB-K participated in designing the study, data-collection and data management, analyses and interpretation of data and writing the article. PVdV participated in designing the study, patient inclusion, providing a clinical perspective and critically revising the article. $\mathrm{RH}$ participated in designing the study, providing a clinical perspective and performing laboratory examinations. HK participated in designing the study, providing a methodological and clinical perspective and critically revising the article. JvdP participated in designing the study, supporting data analyses, providing a methodological perspective and critically revising the article.

Competing interests None.

Patient consent Obtained.

Ethics approval Ethics committee of Medisch Spectrum Twente.

Provenance and peer review Not commissioned; externally peer reviewed.

Data sharing statement The data in the current manuscript were part of the thesis of MB-K (http://doc.utwente.nl/61073/1/thesis_M_Brusse_Keizer.pdf).

Open Access This is an Open Access article distributed in accordance with the Creative Commons Attribution Non Commercial (CC BY-NC 4.0) license, which permits others to distribute, remix, adapt, build upon this work noncommercially, and license their derivative works on different terms, provided the original work is properly cited and the use is non-commercial. See: http:// creativecommons.org/licenses/by-nc/4.0/

\section{REFERENCES}

1. Soler-Cataluna JJ, Martinez-Garcia MA, Roman SP, et al. Severe acute exacerbations and mortality in patients with chronic obstructive pulmonary disease. Thorax 2005;60:925-31.

2. Donaldson GC, Seemungal TA, Bhowmik A, et al. Relationship between exacerbation frequency and lung function decline in chronic obstructive pulmonary disease. Thorax 2002;57:847-52.

3. Miravitlles M, Ferrer M, Pont A, et al. Effect of exacerbations on quality of life in patients with chronic obstructive pulmonary disease: a 2 year follow up study. Thorax 2004;59:387-95.

4. Wilson R. Bacterial infection and chronic obstructive pulmonary disease. Eur Respir J 1999;13:233-5.

5. Restrepo Ml, Anzueto A. Macrolide antibiotics for prevention of chronic obstructive pulmonary disease exacerbations: are we there yet? Am J Respir Crit Care Med 2014;190:1-2.
6. El Moussaoui R, Roede BM, Speelman P, et al. Short-course antibiotic treatment in acute exacerbations of chronic bronchitis and COPD: a meta-analysis of double-blind studies. Thorax 2008;63:415-22.

7. Wilson R. Bacteria, antibiotics and COPD. Eur Respir J 2001;17:995-1007.

8. Goossens H, Ferech M, Vander SR, et al. Outpatient antibiotic use in Europe and association with resistance: a cross-national database study. Lancet 2005;365:579-87.

9. Puhan MA, Vollenweider D, Latshang T, et al. Exacerbations of chronic obstructive pulmonary disease: when are antibiotics indicated? Respir Res 2007;8:30.

10. Vollenweider DJ, Jarrett $\mathrm{H}$, Steurer-Stey CA, et al. Antibiotics for exacerbations of chronic obstructive pulmonary disease. Cochrane Database Syst Rev 2012;12:CD010257.

11. Global strategy for the Diagnosis, Management and Prevention of COPD, Global Initiative for Chornic Obstructive Pulmonary Disease (GOLD). 2013.

12. Anthonisen NR, Manfreda J, Warren CP, et al. Antibiotic therapy in exacerbations of chronic obstructive pulmonary disease. Ann Intern Med 1987;106:196-204.

13. Hirschmann JV. Do bacteria cause exacerbations of COPD? Chest 2000;118:193-203.

14. Hirschmann JV. Bacteria and COPD exacerbations redux. Chest 2001;119:663-7.

15. Quon BS, Gan WQ, Sin DD. Contemporary management of acute exacerbations of COPD: a systematic review and metaanalysis. Chest 2008;133:756-66.

16. Niewoehner DE, Erbland ML, Deupree RH, et al. Effect of systemic glucocorticoids on exacerbations of chronic obstructive pulmonary disease. Department of Veterans Affairs Cooperative Study Group. N Engl J Med 1999;340:1941-7.

17. Davies L, Angus RM, Calverley PM. Oral corticosteroids in patients admitted to hospital with exacerbations of chronic obstructive pulmonary disease: a prospective randomised controlled trial. Lancet 1999;354:456-60.

18. Maltais F, Ostinelli J, Bourbeau J, et al. Comparison of nebulized budesonide and oral prednisolone with placebo in the treatment of acute exacerbations of chronic obstructive pulmonary disease: a randomized controlled trial. Am J Respir Crit Care Med 2002;165:698-703.

19. Llor C, Moragas A, Hernandez S, et al. Efficacy of antibiotic therapy for acute exacerbations of mild to moderate chronic obstructive pulmonary disease. Am J Respir Crit Care Med 2012;186:716-23.

20. Miravitlles M, Moragas A, Hernandez S, et al. Is it possible to identify exacerbations of mild to moderate COPD that do not require antibiotic treatment? Chest 2013;144:1571-7.

21. Van der Valk P, Monninkhof E, van der Palen J, et al. Clinica predictors of bacterial involvement in exacerbations of chronic obstructive pulmonary disease. Clin Infect Dis 2004;39:980-6.

22. Lim WS, van der Eerden MM, Laing $R$, et al. Defining community acquired pneumonia severity on presentation to hospital: an international derivation and validation study. Thorax 2003;58:377-82

23. Effing $\mathrm{T}$, Kerstjens $\mathrm{H}$, van der Valk $\mathrm{P}$, et al. (Cost)-effectiveness of self-treatment of exacerbations on the severity of exacerbations in patients with COPD: the COPE II study. Thorax 2009;64:956-62.

24. Stockley RA, Bayley D, Hill SL, et al. Assessment of airway neutrophils by sputum colour: correlation with airways inflammation. Thorax 2001;56:366-72.

25. Isenberg HD. Clinical microbiology procedures handbook. 2nd ed, ASM press, Washington DC 2004.

26. Stolz D, Christ-Crain M, Bingisser R, et al. Antibiotic treatment of exacerbations of COPD: a randomized, controlled trial comparing procalcitonin-guidance with standard therapy. Chest 2007;131:9-19.

27. Schunemann HJ, Goldstein R, Mador MJ, et al. A randomised trial to evaluate the self-administered standardised chronic respiratory questionnaire. Eur Respir J 2005;25:31-40.

28. van der Molen T, Willemse BW, Schokker S, et al. Development, validity and responsiveness of the Clinical COPD Questionnaire. Health Qual Life Outcomes 2003;1:13.

29. Kocks JW, Tuinenga MG, Uil SM, et al. Health status measurement in COPD: the minimal clinically important difference of the clinica COPD questionnaire. Respir Res 2006;7:62.

30. Assicot M, Gendrel D, Carsin H, et al. High serum procalcitonin concentrations in patients with sepsis and infection. Lancet 1993;341:515-18.

31. Stolz D, Christ-Crain M, Morgenthaler NG, et al. Copeptin, C-reactive protein, and procalcitonin as prognostic biomarkers in acute exacerbation of COPD. Chest 2007;131:1058-67.

32. Daniels JM, Schoorl M, Snijders D, et al. Procalcitonin vs C-reactive protein as predictive markers of response to antibiotic therapy in acute exacerbations of COPD. Chest 2010;138:1108-15. 